\title{
A POSSIBILIDADE DE MITIGAR A GARANTIA CONSTITUCIONAL DA VITALICIEDADE
}

\author{
THE POSSIBILITY OF MITIGATE THE CONSTITUTIONAL GUARANTEE OF \\ LIFETIME
}

\author{
Marco Eduardo Chaves da Silva 1 \\ Marcelo André Azevedo Veras Barrozo ${ }^{2}$
}

\begin{abstract}
RESUMO: O presente trabalho se propõe em analisar e compreender a garantia constitucional da vitaliciedade, a qual possui previsão legal no artigo 95 inciso I da Constituição Federal de 88, verificando se existe a possibilidade em mitigar tal garantia. Ocorre que esta garantia é destinada aos juízes, membros do Ministério Público e os Ministros do Tribunal de Contas da União, tem por finalidade precípua a proteção do exercício da função jurisdicional e ainda, assegurar a independência e liberdade da instituição, todavia, constata-se que alguns magistrados, utilizam desta garantia constitucional como forma de encorajamento no sentido de realizarem práticas inadequadas à profissão, usando tal prerrogativa como forma de escudo, fatos estes impulsionados pela previsão da pena disciplinar de aposentadoria compulsória, descrita no artigo 42 inciso V da Lei Complementar № 35 que dispõe sobre a Lei Orgânica da Magistratura Nacional. Nesse artigo, houve a limitação em abordar apenas os casos envolvendo os magistrados, fazendo uma verificação se o uso desta prerrogativa promove um encorajamento por parte dos transgressores no cometimento de condutas ilícitas. Neste mesmo contexto, constata-se que a referida garantia possui sua nascente na carta magna, possuindo proteção constitucional, istoé, para que haja qualquer modificação, deve ser observado os princípios constitucionais, dentre os quais se destaca a Proibição ao Retrocesso, princípio este que será abordado no decorrer deste artigo.
\end{abstract}

Palavras-chave: Vitaliciedade. Mitigar. Aposentadoria Compulsória. Proibição aoRetrocesso.

ABASTRACT: The present work aims to analyze and understand the constitutional guarantee of lifetime, which has a legal provision in article 95, item I of the Federal Constitution of 88, verifying whether there is a possibility to mitigate such guarantee. It so happens that this guarantee is intended for judges, members of the Public Prosecution Service and the Ministers of the Federal Court of Auditors, its main purpose is to protect the exercise of the jurisdictional function and also to ensure the independence and freedom of the institution, however, it appears that some magistrates use this constitutional guarantee as an encouragement to carry out practices inappropriate to the profession, using this prerogative as a form of shield, facts driven by the provision of the disciplinary penalty of compulsory retirement, described in article 42 , item $\mathrm{V}$ of the Complementary Law No. 35 which provides for the Organic Law of the National Judiciary. In this article, there was a limitation in addressing only cases involving magistrates, verifying whether the use of this prerogative promotes encouragement on the part of transgressors in the commission of illegal conduct. In this same context, it appears that the aforementioned guarantee has its source in the magna, having constitutional protection, that is, for any modification to be made, the constitutional principles must be observed, among which the Prohibition of Setback stands out. whichwill be covered throughout this article.

Keywords: Vitality. Mitigate. Compulsory Retirement. Backward Prohibition.

\footnotetext{
${ }^{1}$ Acadêmico de Direito. Faculdade Interamericana de Porto Velho-UNIRON. E-mail: marcoeduardo.s@gmail.com.

2 Prof. Orientador. Especialista em Docência do Ensino Superior; Professor; Advogado. E-mail: marcelo.barrozo@uniron.edu.br
} 


\section{INTRODUÇÃO}

A Constituição Federal de 88 trouxe expressamente no artigo 95, um rol de garantias destinadas aos juízes, sendo elas: Vitaliciedade, Inamovibilidade e Irredutibilidade de subsídios ${ }^{3}$.

Tais garantias, as quais são inerentes ao cargo de juiz, também são destinadas aos membros do Ministério Público e os Ministros do Tribunal de Contas da União. Aquelas, possuem como finalidade precípua, a proteção do exercício da função jurisdicional e ainda, assegurar a independência e liberdade da instituição.

Ocorre que o gozo de tal prerrogativa com o propósito real, inegavelmente que vem a cumprir com o que foi proposto, no entanto, alguns magistrados, utilizam desta garantia constitucional como forma de encorajamento no sentido de realizarem práticas inadequadas à profissão, usando tal prerrogativa como forma de escudo, poiso cargo, o qual é vitalício, lhes proporciona segurança duradoura, isto é, de acordo com a própria acepção da palavra, é destinado a durar a vida toda.

Isso ocorre porque a Lei complementar № 35, a qual dispõe sobre a Lei Orgânica da Magistratura Nacional prevê no artigo 42, inciso $\mathrm{V}^{4}$, como forma de punição, a pena disciplinar de aposentadoria compulsória com vencimentos proporcionais ao tempo de serviço. Fato é que o referido dispositivo legal mais se assemelha a uma recompensa do que propriamente uma sanção.

Verifica-se a existência de uma problemática, a qual se faz necessária uma correção, quer seja pela supressão do inciso da Lei complementar, citada anteriormente, ou talvez modificá-lo seja a solução. Entretanto, nos deparamos com algumas barreiras, como por exemplo, o fato da vitaliciedade ser uma garantia constitucional cercada de proteções, dentre as quais se destaca o Princípio Constitucional da Proibição do Retrocesso. 5

Diante desse embaraço, torna-se imperioso identificar e compreender as razões que consubstanciam para uma possível mitigação da vitaliciedade, na medida em que tal

${ }^{3}$ BRASIL. Constituição (1988). Constituição da República Federativa do Brasil. Brasília, DF: Senado Federal: Centro Gráfico, 1988. Disponível em: http://www.planalto.gov.br/ccivil_03/constituicao/constituicao.htm. Acesso em 07 abril 202I.

${ }^{4}$ BRASIL. Lei complementar n. 35, de 14 de março de 1979, Dispõe sobre a Lei Orgânica da Magistratura Nacional. Disponível em: http://www.planalto.gov.br/ccivil_03/leis/lcp/lcp35.htm. Acesso em o7 abril de 202I. ${ }^{5}$ MARTINS, Flávio $4^{\underline{a}}$ edição, Curso de Direito Constitucional. Disponível em: https://integrada.minhabiblioteca.com.br/\#/books/9788553617883/cfi/953!/4/4@o.oo:o.ooAcesso em i6. junho 2021. 
enfraquecimento não afronte os princípios constitucionais vigentes.

Ao longo deste artigo, será realizada uma análise acerca da garantia constitucional da vitaliciedade e seus fundamentos legais, bem como de uma verificação de dados estatísticos, os quais apresentam a frequente prática de puniçãode magistrados com a pena disciplinar de aposentadoria compulsória. Também será inspecionado se o dispositivo legal que garante a aposentadoria compulsória aos magistrados pode influenciá-los na prática de determinadas condutas incoerentes com o cargo ao qual exercem. Além disso, será demonstrado os casos concretos em que magistrados são punidos com a aposentadoria compulsória após restar comprovada a prática de conduta criminosa.

Por fim, será efetuada uma explanação dos meios protetivos da vitaliciedade citando os possíveis pontos que impedem a diminuição ou supressão das referidas garantias constitucionais.

Diante disso, será elaborada uma exposição de motivos que fortalecem a probabilidade de ser feita a alteração no texto de lei, fazendo um paralelo com as possíveis barreiras que a referida adequação possa vir a encontrar.

\section{DOS MATERIAIS E MÉTODOS APLICADOS}

O método de pesquisa utilizado para elaborar este projeto, se deu através de um método científico dedutivo, o qual possibilita a realização da busca da verdade de modo coerente e bastante consistente. Busca-se aqui analisar e interpretar os ditameslegais, bem como confrontar essa problemática aqui abordada, expondo de maneira clara as eventuais desvantagens que a aplicação desta penalidade causa para o sistema judiciário e para a população como um todo.

Com relação à natureza desta pesquisa, pretende-se aqui elaborar um trabalho de conclusão de curso bem fundamento, tendo por base todo o arcabouço jurídico vigente, buscando contribuir com a ciência jurídica através de novas reflexõesvoltadas a evolução da sociedade.

No tocante a abordagem, será empregada a combinação de qualidade e quantidade, utilizando o sistema qualiquantitativo, tendo em vista que será abordado um conglomerado de ideias e verificações técnicas acerca desta problemática, expondo os casos reais em que a penalidade é aplicada e fazendo sempre um questionamento acerca da 
legalidade de tal aplicação.

No que concerne aos objetivos técnicos, a finalidade aqui é demonstrar de que forma esta penalidade vem sendo aplicada, demonstrando também quais são os princípios legais que asseguram esta aplicação e evidenciar a possibilidade de se mitigar, isto é, diminuir a garantia constitucional que acoberta tal dispositivo.

No que se refere aos procedimentos técnicos, a base da fundamentação partirá daquilo que já possui registros bibliográficos, entretanto, será utilizado também todos os meios legais de pesquisa, tais como: jurisprudência, súmulas, processos judiciais, artigos científicos, materiais confiáveis disponibilizados na internet, dentre outros.

\section{GARANTIA CONSTITUCIONAL DA VITALICIEDADE}

Esta garantia, a qual não se confunde com a estabilidade, encontra previsão legal no artigo 95 inciso I da Constituição Federal de 1988, in verbis:

Art. 95. Os juízes gozam das seguintes garantias:

I - Vitaliciedade, que, no primeiro grau, só será adquirida após dois anos de exercício, dependendo a perda do cargo, nesse período, de deliberação do tribunal a que o juiz estiver vinculado, e, nos demais casos, de sentença judicial transitada em julgado;

Vitaliciedade significa que: passado o período de dois anos de entrada em exercício no cargo de juiz, o magistrado, somente perderá o cargo se houver sentença judicial transitada em julgado, onde se assegure os princípios do contraditório e da ampla defesa. Trata-se de uma garantia que apresenta maior robustez que a estabilidade, garantia destinada aos servidores públicos, onde define que para o juiz perder o cargo, faz-se necessário uma decisão do tribunal que o juiz estiver vinculadoe em determinados casos tidos como mais complexos, exige uma sentença irrecorrível.

Convém destacar que a exigência de aguardar o período de dois anos é apenas para os juízes de primeiro grau, aqueles que foram investidos no cargo através de um concurso público de provas e títulos, exigência esta não aplicada nos casos em que os juízes forem empossados no cargo através do quinto constitucional, nesta ocasião, os magistrados

\footnotetext{
${ }^{6}$ BRASIL. Constituição (1988). Constituição da República Federativa do Brasil. Brasília, DF: Senado Federal: Centro Gráfico, 1988. Disponível em: http://www.planalto.gov.br/ccivil_03/constituicao/constituicao.htm.
} Acesso em o7 abril 2021. 
tornam-se vitalícios no ato da posse.

Em que pese a vitaliciedade seja destinada aos juízes, conforme se afirma o dispositivo retromencionado, esta garantia não pode ser confundida com as prerrogativas do magistrado as quais encontram previsão legal no artigo 33 da LOMAN, aquela tem a finalidade de assegurar o cargo de juiz enquanto esta tem o condão de proteger a pessoa física do juiz enquanto este permanecer no cargo. ${ }^{7}$

De modo a compreender mais acerca desta garantia, André Ramos Tavares ensina que:

O direito a vitaliciedade atribuído a cada magistrado, v.g., decorre da cláusula da divisão funcional dentro do Estado. Seu fundamento, portanto, está mecessária "independência" que deve se formar entre os chamados "Poderes". 8

Percebe-se que a finalidade elementar desta garantia é a independência funcional de forma que assegure o perfeito andamento da função jurisdicional, todavia,é atribuída a cada magistrado, tendo em vista que este é a figura que representa o Estado na função jurisdicional.

Além disso, esta independência a que se refere capaz de assegurar a atividade jurisdicional se baseia na própria lei e limita-se nela, impossibilitando que omagistrado seja contrário aos seus fundamentos, isto é, a limitação da independênciafuncional é a própria lei.

O juiz está livre para decidir a lide de acordo com o seu entendimento, no entanto, está obrigado a seguir as diretrizes legais, como por exemplo a fundamentação, isto é, a exposição de motivos que formaram o seu convencimento.

Corrobora com o que foi descrito anteriormente, o posicionamento do professor Rodrigo César Rebello, o qual leciona que:

Juízes só perdem o cargo por sentença judicial transitada em julgado do tribunal ao qual estão vinculados. Em primeiro grau a vitaliciedade adquire- se após dois anos de exercício. Esse período é denominado estágio probatório. Os integrantes dos tribunais tornam-se vitalícios a partir da posse, caso já não gozem dessa garantia constitucional. Adquirida a vitaliciedade, é necessária a propositura de uma ação civil própria para a perda do cargo. Durante o estágio probatório, os juízes podem perder o cargo por deliberação do Tribunal a que estiver vinculado.

\footnotetext{
7 BRASIL. Lei complementar n. 35, de 14 de março de 1979, Dispõe sobre a Lei Orgânica da Magistratura Nacional. Disponível em: http://www.planalto.gov.br/ccivil_03/leis/lcp/lcp35.htm. Acessoem o7 abril de 202I. 8 RAMOS, André Tavares, Manual do Poder Judiciário Brasileiro. Disponível em: https://integrada.minhabiblioteca.com.br/\#/books/9788502148277/cfi/238!/4/4@o.oo:37.9. Acesso em I6
} junho.2021. 
Ministros do Supremo Tribunal Federal e Membros do Conselho Nacional de Justiça, em caso de crimes de responsabilidade, só perderão o cargo por deliberação do Senado Federal (CF, art. 52, II). ${ }^{9}$

Convém salientar que esta garantia também possui como significado demonstrar que o mero procedimento administrativo não é suficiente para afastar o magistrado, pois, tão logo o juiz se torne vitalício, ou seja, logo após o estágio probatório de 02 anos, é exigido um processo judicial trânsito em julgado para que seja aplicada a pena de demissão.

Ademais, quando se refere aos Ministros do Supremo Tribunal Federal e aos Membros do Conselho Nacional de Justiça que porventura cometerem crime de responsabilidade, a CF/88 exige que estes sejam processados e julgados de maneiraprivativa pelo Senado Federal, tal afirmação encontra respaldo legal no artigo 52 inciso II da Constituição Federal. ${ }^{\text {1o }}$

\section{LEI ORGÂNICA DA MAGISTRATURA NACIONAL}

A LOMAN como é popularmente conhecida, trata-se da Lei Complementar № 35 de I4 de março de 1979, Lei esta que regulamenta a organização do Poder Judiciário."

Esta referida Lei, além de possuir a função citada anteriormente, dispõe também sobre as garantias, vantagem, vencimentos, prerrogativas, direitos, deveres $e$ as penalidades concernentes aos magistrados.

Convém destacar que a referida Lei foi promulgada no ano de 1979, período este que o Brasil esteve sob o regime da Ditadura Militar, isto é, anterior à Constituição Federal de 1988. A Carta Magna e, mais recentemente as resoluções do CNJ (Conselho Nacional de Justiça) atualizaram algumas normas com a finalidade de trazer mais clareza ao Estatuto da Magistratura, entretanto, é vasta a jurisprudência do Supremo Tribunal Federal no sentido de que a LOMAN foi recepcionada pela CF de 88.

Outrossim, a Constituição Federal vigente, no caput do artigo $93^{12}$, trouxe a

\footnotetext{
9 CÉSAR, Rodrigo Rebello Pinho $\mathrm{I}^{\mathrm{a}}$ edição, Da organização do Estado, dos poderes e histórico das constituições. Disponível em: https://integrada.minhabiblioteca.com.br/\#/ p. I42, Acesso em I6.junho,2021

1o BRASIL. Constituição (1988). Constituição da República Federativa do Brasil. Brasília, DF: Senado Federal: Centro Gráfico, 1988. Disponível em: http://www.planalto.gov.br/ccivil_03/constituicao/constituicao.htm. Acesso em o7 abril 2021.

II BRASIL. Lei complementar n. 35, de 14 de março de 1979, Dispõe sobre a Lei Orgânica da Magistratura Nacional. Disponível em: http://www.planalto.gov.br/ccivil_03/leis/lcp/lcp35.htm. Acesso em o7 abril de 2021.

${ }^{12}$ BRASIL. Constituição (1988). Constituição da República Federativa do Brasil. Brasília, DF: Senado Federal: Centro Gráfico, 1988. Disponível em: http://www.planalto.gov.br/ccivil_03/constituicao/constituicao.htm.
} 
previsão de que o Estatuto da Magistratura fosse criado através de uma Lei Complementar por iniciativa do STF, sendo observado os critérios descritos nos incisos deste referido artigo. Contudo, a exequível atualização ainda não foi concretizada apesar de uma tentativa frustrada através de um anteprojeto elaborado e apresentado no final de 2014 pelo ministro Ricardo Lewandowski a partir de propostado ministro Luiz Fux. ${ }^{13}$

Diante da afirmação de que a LOMAN foi promulgada no ano de 1979, pareceútil trazer à baila o princípio de que as Leis são criadas para vigorar por tempo indeterminado, todavia, vale salientar que os usos e costumes não são engessados e se atualizam com o passar dos tempos, essa mudança no direito consuetudinário são fatores motivadores a revisão da literalidade da lei bem como de serem atingidas peloinstituto da ab-rogação ou derrogação, isto é, uma revogação total ou parcial da lei, quando esta não atender mais os princípios que a motivaram sua criação.

É perceptível o entendimento de que a Lei precisa passar por uma atualizaçãotendo em vista a imposição legal prevista na Constituição Federal incluindo também a possibilidade de realizar uma revisão no Capítulo II da referida lei, o qual trata das penalidades que devem ser aplicadas aos magistrados infratores.

\section{APOSENTADORIA COMPULSÓRIA}

A aposentadoria compulsória trata-se de uma penalidade, a qual está prevista no artigo 42 da Lei Complementar № 35 de 14 de março de 1979, a qual foi citada notópico anterior, Lei esta que dispõe sobre a organização do Poder Judiciário. ${ }^{\mathrm{I}}$

A referida Lei previu no inciso $\mathrm{V}$ do artigo supramencionado, a aposentadoria compulsória como sendo uma espécie de pena disciplinar. Além disso, definiu ainda no corpo da Lei, as condições que seriam cabíveis a aplicação desta modalidade de punição, sendo descritas no artigo 56 da LOMAN, in verbis:

Art. 56 - O Conselho Nacional da Magistratura poderá determinar a aposentadoria, com vencimentos proporcionais ao tempo de serviço, do

\footnotetext{
Acesso em o7 abril 2021.

${ }^{13}$ LEWANDOWSKI, Enrique Ricardo (2014) Presidente do Supremo Tribunal Federal. Minuta de Anteprojeto do Estatuto da Magistratura. Disponível em https://www.conjur.com.br/dl/estatuto- magistratura-juizesloman-stf.pdf. Acesso em 26. setembro 2021.

${ }^{14}$ BRASIL. Lei complementar n. 35, de 14 de março de 1979, Dispõe sobre a Lei Orgânica da Magistratura Nacional. Disponível em: http://www.planalto.gov.br/ccivil_03/leis/lcp/lcp35.htm. Acessoem o7 abril de 2021.
} 
magistrado:

I - Manifestadamente negligente no cumprimento dos deveres docargo;

Il - de procedimento incompatível com a dignidade, a honra e o decoro de suas funções;

III - de escassa ou insuficiente capacidade de trabalho, ou cujoproceder

funcional seja incompatível com o bom desempenho das atividades do

Poder Judiciário. ${ }^{15}$

Ao se analisar o aludido dispositivo legal, nota-se que o legislador, em momento algum fez menção a práticas de condutas criminosas, as hipóteses descritas no referido artigo são três, sendo: Manifestadamente negligente no cumprimento dos deveres do cargo, que é sinônimo de descuidado, indiligente e desidioso, ações estas praticadas em pleno exercício das funções inerentes ao cargo, a segunda de procedimento incompatível com a dignidade, honra e o decoro de suas funções, dispositivo este que, o legislador trouxe um pouco mais de subjetividade no tocante ao termo procedimento incompatível, entretanto, tal procedimento deve ser antagônico a dignidade, a honra e o decoro de suas funções, e por fim a conduta de escassa ou insuficiente capacidade de trabalho, ou cujo proceder funcional seja incompatível com o bom desempenho das atividades do Poder Judiciário, possuindo relação direta com os indicadores de desempenho, sendo eles: eficiência, eficácia e efetividade, ou seja, quando o magistrado não produz o suficiente dentro daquilo que é esperado.

Percebe-se que as conjunturas acima descritas, evidenciam hipóteses de condutas brandas sendo estas distintas de atos criminosos, pois, para estas ações tidas como criminosas, a Lei Orgânica da Magistratura Nacional foi enfática em preveros artigos 47 e 26 , in verbis:

Art. 47 - A pena de demissão será aplicada:

I - aos magistrados vitalícios, nos casos previstos no art. 26, I e Il; II aos Juízes nomeados mediante concurso de provas e títulos, enquanto não adquirirem a vitaliciedade, e aos Juízes togados temporários, em caso de falta grave, inclusive nas hipóteses previstas no art. 56 .

Art. 26 - O magistrado vitalício somente perderá o cargo (vetado): I em ação penal por crime comum ou de responsabilidade;

II - Em procedimento administrativo para a perda do cargo nas hipóteses seguintes:

a) exercício, ainda que em disponibilidade, de qualquer outra função, salvo um cargo de magistério superior, público ou particular;

b) recebimento, a qualquer título e sob qualquer pretexto, de

is BRASIL. Lei complementar n. 35, de 14 de março de 1979, Dispõe sobre a Lei Orgânica da Magistratura Nacional. Disponível em: http://www.planalto.gov.br/ccivil_03/leis/lcp/lcp35.htm. Acessoem o7 abril de 2021. 
percentagens ou custas nos processos sujeitos a seu despacho e julgamento

c) exercício de atividade político-partidária. ${ }^{16}$

Diferentemente do que ocorre na penalidade de aposentadoria compulsória com vencimentos proporcionais ao tempo de serviço, onde o legislador descreve condutas do tipo subjetivas, nas quais exige a verificação se a conduta praticada se amolda ao referido dispositivo legal, para a penalidade de demissão, está previsto de forma expressa que será aplicada em ação penal por crime comum ou de responsabilidade e em procedimento administrativo ocorrendo em três hipóteses, sendo elas: cumulação inadequada de cargo público, observada a devida exceção, recebimento de qualquer vantagem nos processos que estiver sob seu julgamento e exercício de atividade político-partidária.

A cumulação inadequada de cargo público, ocorre quando o magistrado passa a possuir mais de um vínculo com a administração, em qualquer outro cargo que não seja a função de magistério superior, isto é, todas outras funções que são vedadas, exceto a função de magistério, onde será configurada a cumulação inadequada mesmo que o magistrado esteja em disponibilidade.

Com relação a recebimento, a qualquer título e sob qualquer pretexto, de percentagens ou custas nos processos sujeitos a seu despacho e julgamento, trata- se do pressuposto de que o magistrado receba qualquer benefício, vantagem, seja ela de natureza pecuniária ou não, em decorrência de despachos e julgamentos que estiver proferindo, neste caso, o recebimento de um benefício, além de configurar hipótese de suspeição do juiz prevista no artigo 145 inciso II do CPC, poderá ensejarna pena de demissão. ${ }^{17}$

A última hipótese da via administrativa, exercício de atividade político- partidária, dispensa explicação pois a própria leitura do dispositivo de lei torna possívelo entendimento.

Nota-se que de acordo com o artigo supracitado, a perda do cargo ocorrerá mediante o procedimento administrativo, conforme foi explanado anteriormente e emação penal por crime comum ou de responsabilidade, nesta circunstância, o regulamento não faz

\footnotetext{
${ }^{16}$ BRASIL. Lei complementar n. 35, de 14 de março de 1979, Dispõe sobre a Lei Orgânica da Magistratura Nacional. Disponível em: http://www.planalto.gov.br/ccivil_03/leis/lcp/lcp35.htm. Acesso em o7 abril de 2021.

17 BRASIL. Lei 13.105, de 16 de março de 2015, Código de Processo Civil. Disponível em: http://www.planalto.gov.br/ccivil_03/_ato2015-2018/2015/lei/li3105.htm. Acesso em i6. junho 2021.
} 
a exigência de que o crime praticado esteja no rol da Lei dos Crimes Hediondos, sequer em Leis Penais Extravagantes, ou seja, o legislador deu mais abrangência a este dispositivo quando realizou apenas a previsão da prática de crime comum ou de crime de responsabilidade.

\section{ESTUDO DE CASO}

Nota-se que em observância aos preceitos legais citados anteriormente, ao lermos os dispositivos que regulam a aplicação da penalidade de aposentadoria compulsória, não observamos a previsão de que ela possa ser aplicada quando houver o cometimento de algum ato criminoso, todavia, não é o que vem ocorrendo no âmbito prático.

Corroborando com o que fora mencionado no parágrafo anterior, destacamos aqui algumas matérias do ano de 2021, sendo 03 delas veiculadas no site oficial do Conselho Nacional de Justiça, pela agência CNJ de notícias, as quais apresentam as seguintes manchetes: "CNJ aposenta desembargador acusado de venda de sentenças em Tocantins ${ }^{18}$ "; "CNJ confirma aposentadoria compulsória de juiz de MatoGrosso" ${ }^{19}$; "Desembargadora do TJMS recebe pena de aposentadoria compulsória" ${ }^{20}$. E uma transmitida pelo site Olharjurídico, a qual foi publicada da seguinte forma: "Ministro restabelece aposentadoria do ex-desembargador condenado por vender sentença", ${ }^{21}$

O primeiro editorial, CNJ aposenta desembargador acusado de venda de sentenças em Tocantins. ${ }^{22}$ Neste caso, o magistrado foi acusado pelo recebimento de vantagem indevida, prolação de decisões judiciais, celebração de acordo financeiro e ordem

\footnotetext{
${ }^{18}$ ANDRADE, Paula (202I) CNJ aposenta desembargador acusado de venda de sentenças em Tocantins. Disponível em: https://www.cnj.jus.br/cnj-aposenta-desembargador-acusado-de-venda-de- sentencas-emtocantins/. Acesso em I6 junho 2021.

${ }^{19}$ ANDRADE, Paula (202I) CNJ confirma aposentadoria compulsória de juiz de Mato Grosso. Disponível em: https://www.cnj.jus.br/cnj-confirma-aposentadoria-compulsoria-de-juiz-do-mato-grosso/. Acesso em 16 junho 2021.

${ }^{20}$ MELO, Jeferson (2021) Desembargadora do TJMS recebe pena de aposentadoria compulsória. Disponível em: https://www.cnj.jus.br/desembargadora-do-tjms-recebe-pena-de-aposentadoria- compulsoria/. Acesso em i7 junho 2021.

${ }^{21}$ SANTOS, Arthur da Silva (202I) Ministro restabelece aposentadoria do ex-desembargadorcondenado por vender sentença. Disponível em: https://www.olharjuridico.com.br/noticias/exibir.asp?id=46064\&noticia = ministro-restabelece-aposentadoriade-ex-desembargador-condenado-por-vender-sentenca\&edicao=I. Acesso em 17 junho 202I.

22 ANDRADE, Paula (2021) CNJ aposenta desembargador acusado de venda de sentenças em Tocantins. Disponível em: https://www.cnj.jus.br/cnj-aposenta-desembargador-acusado-de-venda-de- sentencas-emtocantins/. Acesso em 16 junho 2021.
} 
cronológica de pagamentos de precatórios. O STJ recebeu a denuncia onde foram imputados os crimes de corrupção passiva, concussão e peculato. De acordo com o relator do processo n. ooo2803-24.2016.2.00.00oo, Luiz Fernando Keppen, "ele nomeou parentes no gabinete como assessores e montou um núcleo de venda de decisões judiciais”.

Extrai também da matéria publicada no site oficial do CNJ que em virtude a clareza das provas ficou decidido de forma unânime a aplicação da penalidade de aposentadoria compulsória com vencimentos proporcionais tendo em vista o referido desembargador organizar um esquema de venda de sentenças em seu gabinete. Vale por em destaque neste caso que o magistrado acusado permaneceu afastado de suasfunções desde o ano de 2011 até o dia de seu julgamento que ocorreu no dia 20 de abril de 2021 na $329^{\text {a }}$ seção ordinária, ou seja, o afastamento do magistrado foi mantido por um período de ro anos e findou com a aplicação da penalidade de aposentadoria compulsória com vencimentos proporcionais.

$\mathrm{Na}$ segunda matéria, CNJ confirma aposentadoria compulsória de juiz de Mato Grosso $^{23}$, temos um caso bem similar ao primeiro, onde o magistrado também foi acusado por ter integrado um esquema de venda de decisões judiciais, dentre as quais se destacam a liberação de um acusado de matar o próprio irmão e de uma liminar que soltou um traficante de drogas. "As conversas interceptadas são provas cabais. Não há duvidas do envolvimento do magistrado, não resta alternativa ao $\mathrm{CNJ}$ a não ser confirmar a condenação", afirmou a relatora do processo, Conselheira Tânia Reckziegel, após ler as conversas interceptadas pela polícia.

Neste referido caso, o processo também permaneceu suspenso por o6 anos, desde o ano de 2015, sendo finalizado no dia 23 de março de 2021 durante a $327^{\text {a }}$ seção ordinária, na qual, por decisão unânime, condenaram o magistrado à pena de aposentadoria compulsória com vencimentos proporcionais.

A terceira reportagem afirma: "Desembargadora do TJMS recebe pena de aposentadoria compulsória” ${ }^{24}$. Nesta ocasião, a desembargadora foi acusada de agilizar o

\footnotetext{
${ }^{23}$ ANDRADE, Paula (202I) CNJ confirma aposentadoria compulsória de juiz de Mato Grosso. Disponível em: https://www.cnj.jus.br/cnj-confirma-aposentadoria-compulsoria-de-juiz-do-mato- grosso/. Acesso em i6 junho 2021.

${ }^{24}$ MELO, Jeferson (202I) Desembargadora do TJMS recebe pena de aposentadoria compulsória. Disponível em: https://www.cnj.jus.br/desembargadora-do-tjms-recebe-pena-de-aposentadoria- compulsoria/. Acesso em 17 junho 2021.
} 
cumprimento de habeas corpus que garantia a remoção de seu filho preso preventivamente em uma clínica psiquiátrica, de utilizar veículo descaracterizado do Tribunal de Justiça do MS para transportar o preso (seu filho) até uma clínica psiquiátrica e de comparecer ao presídio na companhia de policiais civis com o intuito de pressionar pela liberação e remoção do seu filho antes do envio do mandado judicial. De acordo com o Conselheiro Luiz Fernando Tomasi Keppen, todas estas acusações, citadas anteriormente, são procedentes e estão concatenadas.

O processo administrativo disciplinar foi instaurado no ano de 2018 , sendo julgado no dia 23 de fevereiro de 2021 durante a $325^{\text {a }}$ seção ordinária do $\mathrm{CNJ}$, com a decisão da maioria dos conselheiros optando em aplicar a penalidade de aposentadoria compulsória com vencimentos proporcionais.

O último editorial, extraído do site Olharjurídico, publicou o seguinte: "Ministro restabelece aposentadoria do ex-desembargador condenado por vender sentença" ${ }^{25}$.Segundo o site o desembargador quando na função de presidente do Tribunal Regional Eleitoral de Mato Grosso, aceitou e cobrou propina para manter a prefeita de Alto Paraguai no cargo. Ele foi indiciado e condenado pelo crime de corrupção passiva no ano de 2015 , sendo que a perda da função pública se deu no ano de 2020por decisão do ex-presidente do Tribunal de Justiça do Mato Grosso, o desembargador Carlos Alberto Alves da Rocha.

Agora neste corrente ano, mais precisamente no dia 14 de abril de 202I, a aposentadoria do ex-desembargador foi restabelecida por uma decisão do ministro Sérgio Kukina, do Superior Tribunal de Justiça, decisão esta que permanecerá até o julgamento do mérito do recurso.

Após a análise das matérias supracitadas, constata-se que a pena de aposentadoria compulsória vem sendo aplicada indiscriminadamente, aplicação esta controversa quando se comparado com os dispositivos legais citados anteriormente, contrário também aos princípios administrativos, dentre os quais se destaca o Princípio da Moralidade Administrativa.

\footnotetext{
${ }^{25}$ SANTOS, Arthur da Silva (2021). Ministro restabelece aposentadoria do ex desembargadorcondenado por vender sentença. Disponível em: https://www.olharjuridico.com.br/noticias/exibir.asp?id=46o64\&noticia $=$ ministro-restabeleceaposentadoria-de-ex-desembargador-condenado-por-vender-sentenca\&edicao=I. Acesso em I7junho 2021 .
} 
Em pesquisa no sitio eletrônico https://www.cnj.jus.br/, endereço eletrônico institucional do CNJ (Conselho Nacional de Justiça) podemos constatar que em menos de o6 meses deste corrente ano (202I), houve a aplicação da pena de aposentadoria compulsória para 02 juízes e 03 desembargadores que cometeram atos criminosos.

\section{UM DEBATE EM EVIDÊNCIA NO PARLAMENTO FEDERAL}

Diante destas contrariedades, as quais vem ocorrendo de maneira muito frequente, o debate ora apresentado no contexto deste referido artigo parece não ser uma pauta já consolidada, pois, constatamos divergências de entendimentos nesse assunto.

Insta trazer à baila o Projeto de Lei Complementar (PLP n. 277/2020) de autoria do Deputado Federal José Nelto, o qual foi apresentado na Câmara dos Deputados dia I4 de dezembro de $2020 .{ }^{26}$

O referido projeto tem por finalidade revogar a pena disciplinar de aposentadoria compulsória e instituir a pena de demissão aos magistrados condenados pela prática de falta disciplinares graves.

Ao analisar o aludido projeto, verifica-se a pretensão em realizar a inserção de 02 (dois) novos parágrafos no artigo 42 da LOMAN, sendo: A possibilidade de aplicar a medida cautelar de afastamento do exercício do cargo por um período de até 60 dias, sem prejuízo da remuneração, medida esta, para assegurar que o magistrado não interfira na apuração da irregularidade, investigada via processo disciplinar e a hipótese em que haja a previsão da aplicação da penalidade de demissão, neste caso,o magistrado terá que ressarcir aos cofres públicos a remuneração que tiver auferida durante o período que permaneceu afastado.

Também foi proposto uma inserção de 03 (três) alíneas no artigo 26 da Lei Complementar № 35, artigo este que trata das hipóteses em que o magistrado vitalíciopoderá perder o cargo.

A anexação destas alíneas no artigo retromencionado não configuram uma

\footnotetext{
${ }^{26}$ NELTO, José Lagares das Mercês (2020). Projeto de Lei complementar n. 277, de 14 de dezembro de 2020. Revoga a pena disciplinar de aposentadoria compulsória e institui a pena de demissão aos magistrados condenados pela prática de faltas disciplinares graves. Disponívelem: https://www.camara.leg.br/proposicoesWeb/fichadetramitacao?idProposicao=2266915. Acesso em I6. setembro 2021.
} 
inovação da Lei, isto é, apesar de haver uma modificação na redação do artigo, aquiloque se propunha em inserir já existe no corpo da Lei.

Para ficar mais clara a compreensão, esclareço aqui de uma forma bem sintética: atualmente, as alíneas que se almeja inserir, já se encontram na LOMAN, podendo ser localizadas nos incisos I, II e III do artigo 56, artigo este que concede ao CNJ as hipóteses que podem levar a determinação da aposentadoria compulsória do magistrado com vencimentos proporcionais ao tempo de serviço. Entretanto, o Projetode Lei Complementar № $277 / 2020$, não suprimiu os incisos, mas sim, posicionou os referidos dispositivos como forma de alíneas no artigo que trata da penalidade de demissão, sendo ele o artigo 26 da LOMAN, desta forma, neste quesito não houve uma inovação propriamente dita, ocorrendo apenas um posicionamento da norma emlocal diferente de forma que houvesse a revogação da penalidade de aposentadoria compulsória.

Nesta oportunidade, torna-se conveniente realizar uma citação acerca da fundamentação utilizada para realizar a elaboração deste projeto de Lei Complementar, nestes termos:

Ressalta-se que entre os anos de 2008 e 2018, 47 magistrados foram punidos com a aposentadoria compulsória pelo Conselho Nacional de Justiça, os quais receberam, em um período de seis meses, em salário bruto o valor total de R $\$$ io milhões. Entre os 47 magistrados faltosos, estão juízes, desembargadores e até um ex-ministro do Superior Tribunal de Justiça, acusados de crimes como venda de sentença, desvio de dinheiro público, tráfico de influência, além de outras faltas disciplinares. Em que pese a tese da não recepção da pena de demissão, com a recente aprovação da Emenda Constitucional no 103/2019 - Reforma de Previdência, a aposentadoria compulsória como punição a juízes foi retirada da Magna Carta. Dessa forma, diante da inércia da ação legislativa necessária pelo Poder Judiciário de acabar de vez com esse benefício imoral, a presente proposição legislativa tem por objetivo revogar a pena disciplinar de aposentadoria compulsória e instituir a pena de demissão aos magistrados condenados pela prática de faltas disciplinares graves. ${ }^{27}$

Corroborando com a justificativa supra mencionada, de acordo com a revista CONJUR, em 2004 foi realizada uma estatística sobre a quantidade de processos envolvendo magistrados no polo passivo da ação, a qual obteve uma estimativa de mais de cem casos. ${ }^{26}$

Por conseguinte, sem querer aqui generalizar, são notórios os casos em que alguns

\footnotetext{
${ }^{27}$ NELTO, José Lagares das Mercês (2020). Projeto de Lei complementar n. 277, de 14 de dezembrode 2020. Revoga a pena disciplinar de aposentadoria compulsória e institui a pena de demissão aos magistrados condenados pela prática de faltas disciplinares graves. Disponível em: https://www.camara.leg.br/proposicoesWeb/fichadetramitacao?idProposicao=2266915. Acesso em i6. setembro 2021.
} 
magistrados utilizam suas prerrogativas para cometerem atos inconvenientes/inadequados de suas funções, e, a prática adotada para se punir o transgressor, de acordo com a Lei é o afastamento temporário do cargo e/ou um convite a aposentadoria antecipada. Tal procedimento gera consequências imediatas,como por exemplo prejuízo aos cofres públicos, na medida em que os salários continuam sendo pagos na integralidade durante o período do afastamento, e permanecem, ainda que de forma proporcional ao tempo de serviço, quando aplicadaa pena de aposentadoria compulsória.

Soma-se a isso, o contraponto existente no fato de que a aposentadoria compulsória se apresenta como uma penalidade que tem caráter punitivo, todavia se assemelha mais com um galardão e, nas palavras do Parlamentar Sr. José Nelto, trata-se de um "benefício imoral" o qual deve findar com sua revogação.

No que concerne a tramitação do PLP n. 277/2020, após verificação no endereço eletrônico institucional da Câmara dos Deputados, https://www.camara.leg.br/proposicoesWeb/fichadetramitacao?idProposicao=22669I 5, certifica-se que o reportado projeto foi devolvido no dia I6 de junho de 202I por contrariar o artigo 93 da Constituição Federal.

Ocorre que a Carta Magna previu no caput do artigo $93^{28}$ que a Lei Complementar a qual irá dispor sobre o Estatuto da Magistratura, será de iniciativa doSupremo Tribunal Federal, contudo, o referido PLP foi antagônico ao que prediz o mandamento constitucional, ocasionando assim o seu arquivamento.

Entretanto, ainda não é o fim, o despacho da Mesa Diretora apontou que houve aqui uma inconstitucionalidade formal, ou seja, deixou de ser observado regras ou procedimento previsto na Constituição para elaboração de uma norma, todavia, como não se trata de inconstitucionalidade material, isto é, relativo ao conteúdo, princípios, etc.., existe a possibilidade deste projeto se tornar efetivamente uma Lei Complementar desde que seja apresentado pela via correta, qual seja, uma propostade Emenda Constitucional.

Por fim, convém pôr em destaque as datas em que foi protocolado o PLP $\mathrm{n}$. $277 / 2020$ e a data da sua devolução, sendo respectivamente nos dia I4 de dezembrode 2020 e

${ }^{28}$ BRASIL. Constituição (1988). Constituição da República Federativa do Brasil. Brasília, DF: Senado Federal: Centro Gráfico, 1988. Disponível em: http://www.planalto.gov.br/ccivil_03/constituicao/constituicao.htm. Acesso em o7 abril 202I. 
dia 16 de junho de 202I, reafirmando que a discussão pautada trata-se de um tema atual e extremamente relevante que por ora encontra-se na condição de arquivado ao se analisar sobre a égide da formalidade, apesar de latente quando analisamos sobre a via informal que pulsa na Casa do Povo.

\section{A PEC 32}

Conforme exposto anteriormente, a matéria apresentada por meio do projeto de Lei Complementar № 277/2020 não poderia ser formalizada por esta via tendo em vista a expressa previsão constitucional, na qual define que a iniciativa deva ser do Supremo Tribunal Federal, entretanto, outra possibilidade na sua execução seria por intermédio de uma Proposta de Emenda Constitucional.

A vista disso, torna conveniente expor a Proposta de Emenda a Constituição Federal № 32 de autoria do Poder Executivo, apresentada no dia 03 de setembro de 2020, que altera disposições sobre servidores, empregados públicos e organização administrativa a qual possui como objetivo conferir maior eficiência, eficácia e efetividade à atuação do Estado. ${ }^{29}$

Tal Proposta de Emenda a Constituição, elaborada pelo Ministro da Economia Paulo Roberto Nunes Guedes, vem se popularizando como aquela que será a reforma administrativa no serviço público, trazendo uma série de inovações para a máquina estatal.

Dentre as pautas expostas na referida PEC 32, destaca-se a inserção da alínea $f$ do inciso XXIII ao artigo 37 da Constituição Federal de 1988, in verbis:

\footnotetext{
XXIII - é vedada a concessão a qualquer servidor ou empregado da administração pública direta ou de autarquia, fundação, empresa pública ou sociedade de economia mista de:
}

f) aposentadoria compulsória como modalidade de punição; ${ }^{30}$

$\mathrm{O}$ aludido dispositivo possui o intento em abolir do ordenamento jurídico a possibilidade de se conceder a aposentadoria compulsória como uma forma de sansão.

\footnotetext{
${ }^{29}$ GUEDES, Paulo Roberto Nunes (2020). Proposta de Emenda a Constituição № 32, altera disposições sobre servidores, empregados públicos e organização administrativa Disponível em: https://www.camara.leg.br/proposicoesWeb/fichadetramitacao?idProposicao=2262083. Acesso em 21. setembro 2021.

${ }^{30}$ Ibidem.
} 
Nota-se que apesar de conservar o mesmo objetivo do PLP n. 277/2020, retratado no tópico anterior, desta vez, esta proposta cumpre efetivamente os requisitos legais exigidos na atual carta magna, aqueles que foram apontados no ato da devolução e arquivamento do referido projeto de Lei Complementar, qual seja a possibilidade de se executar mediante uma Proposta de Emenda à Constituição.

Ademais, neste presente momento, foram apresentados por alguns Parlamentares diversos requerimentos nos quais solicitam anexação da proposta de Emenda a Constituição bem como a realização de audiências públicas tendo em vista a extrema relevância deste tema o qual é tratado nesta referida proposta. Além disso,convém destacar que as últimas movimentações datam o mês de setembro deste corrente ano onde foram criadas comissões especiais destinadas a proferir parecer ás propostas de emenda à constituição, evidenciando assim a atualidade do tema emquestão.

\section{PRINCÍPIO CONSTITUCIONAL DA PROIBIÇÃO DO RETROCESSO}

Os princípios constitucionais são instrumentos que guardam os valores fundamentais, são eles que norteiam a elaboração e vigência das normas estabelecendo os limites que estas devam obedecer. $\mathrm{Na}$ Constituição Federal vigente, podemos encontrar os princípios explícitos, isto é, expressos no corpo da carta magna e os princípios implícitos, sendo aqueles que se extrai com a leitura da normativa constitucional.

O princípio da Proibição do Retrocesso, também chamado de vedação ao retrocesso ou efeito cliquet, trata-se de um fundamento implícito que tem por finalidade impedir que se retroaja naquilo que já foi alcançado. Flávio Martins explica em sua obra o porquê se utiliza esta nomenclatura de origem francesa:

A expressão francesa "efeito cliquet", numa tradução literal, seria "efeito catraca" (expressão que, decorrente do alpinismo, significa o movimento que só permite ao alpinista ir para cima, ou seja, subir, já que os pinos de sustentação estão sempre acima do alpinista). A expressão foi usada na jurisprudência do Conselho Constitucional francês (cliquet effet) para fornecerproteção especial para certas liberdades, declarando inconstitucional a lei que, em vez de torná-los mais eficazes, restringe-nos excessivamente. ${ }^{3 \mathrm{I}}$

Assim, em analogia à prática da atividade desportiva de alpinismo na qual

\footnotetext{
${ }^{31}$ MARTINS, Flávio $4^{\underline{a}}$ edição, Curso de Direito Constitucional. Disponível em: https://integrada.minhabiblioteca.com.br/\#/books/9788553617883/cfi/953!/4/4@o.oo:o.ooAcesso em I6. junho 2021.
} 
possibilita apenas o avanço, e por óbvio, impedindo o seu declínio, uma vez que haja uma conquista de direitos, no sentido lato sensu, não mais se permite a supressão daqueles que já foram alcançados. No entanto, o fato de ter havido uma conquista dedireitos, não impede o legislador de alterá-los no sentido de ampliação, ficando impossibilitado apenas da prática restritiva.

De acordo com a doutrina, o princípio da proibição do retrocesso ou vedação ao retrocesso, possui uma estreita relação como princípio da segurança jurídica. Nas palavras de Celso Antônio Bandeira de Mello, "a segurança jurídica coincide com uma das mais profundas aspirações do ser humano, viabilizando, mediante a garantia de certa estabilidade nas relações jurídicas e da própria ordem jurídica, tanto elaboraçãode projetos de vida, bem como de sua realização, de sorte que desde logo verifica-se que a segurança jurídica decorre da dignidade da pessoa humana". ${ }^{32}$

Este referido princípio, o qual guarda mais correlação com os direitos sociais, previstos no artigo 6o da $\mathrm{CF} / 88$, vai muito além e sua abrangência tem infinitas proporções quando se trata de aquisição de direitos. Corrobora com esta informação,o pensamento do Ministro do Supremo Tribunal Federal, Luís Roberto Barroso, o qualafirma que, "por este princípio, que não é expresso, mas decorre do sistema jurídico constitucional, entende-se que, se uma lei, ao regulamentar um mandamento constitucional, instituir determinado direito, ele se incorpora ao patrimônio da cidadania e não pode ser absolutamente suprimido". ${ }^{33}$

Assim sendo, uma vez conquistados tais direitos, estes não podem ser simplesmente eliminados pelo legislador, se isso acontecesse, certamente haveria um rompimento da segurança jurídica.

Dessa forma, tendo em vista a citação do referido ministro, inferimos que o Princípio da Proibição ao Retrocesso possui uma abrangência que ultrapassa os limites dos direitos sociais, podendo sim ser aplicado à garantia constitucional da vitaliciedade, pois, com o advento da Constituição Federal de 88, houve aqui uma incorporação deste direito, não podendo ser facilmente suprimido.

\footnotetext{
${ }^{32}$ MARTINS, Flávio $4^{\underline{a}}$ edição, Curso de Direito Constitucional. Disponível em: https://integrada.minhabiblioteca.com.br/\#/books/9788553617883/cfi/953!/4/4@0.0o:o.ooAcesso em i6. junho 202I.

33 Ibidem, p. 957 .
} 
No tocante a aposentadoria compulsória, de acordo com a LOMAN, este instituto pertence à categoria das penalidades, portanto, não se trata de um direito, apesar de se assemelhar a um benefício, logo, não está acobertado pelo efeito cliquet podendo sim ser suprimida da referida normativa legal.

\section{CONSIDERAÇÕES FINAIS}

O Presente trabalho se propôs em tratar de forma sucinta sobre a possibilidade de eliminar do ordenamento jurídico a pena de aposentadoria compulsória, examinando se a supressão deste dispositivo pudesse afetar diretamente a garantia constitucional da vitaliciedade.

Foi observado que de acordo com a Lei da Magistratura para a aplicação desta penalidade, a própria lei evidencia hipóteses de condutas brandas sendo estas distintas de atos criminosos, pois, para estas ações tidas como criminosas, a LOMAN foi cristalina em prever o emprego da penalidade de demissão.

Constatou-se também que em menos de 06 meses deste corrente ano (2021), houve a aplicação da pena de aposentadoria compulsória para 02 juízes e 03 desembargadores que cometeram atos criminosos, informação esta extraída do endereço eletrônico institucional do CNJ (Conselho Nacional de Justiça).

Inquestionavelmente, a aposentadoria significa um benefício, fazendo jus aquele que desenvolveu as atividades laborais com muito esforço no decorrer de toda a sua jornada, sendo esta definição um paradoxo ao se comparar a aposentadoria compulsória na qual sua aplicação possui a finalidade de punição, entretanto sua aplicação se assemelha mais a um galardão.

Restou demonstrado com a apresentação do Projeto de Lei Complementar n. 277/2020 e a Proposta de Emenda à Constituição N 32 que o debate ora apresentado no contexto deste referido artigo é um assunto atual e que possui destaque, isto é, não se trata de uma pauta já consolidada. E que a problemática apresentada aqui ecoa nos corredores do Parlamento Federal, evidenciando o senso comum da realidade aqui exteriorizada.

Por fim, foi analisado o Princípio Constitucional da Proibição ao Retrocesso, verificando se este princípio possui abrangência sobre a aposentadoria compulsória, obtendo como resultado que o referido princípio possui abrangência de infinitas proporções 
quando se trata de aquisição de direitos, entretanto, a aposentadoria compulsória aplicada aos magistrados, possui um caráter punitivo e está descrita no rol das penalidades e não como um direito.

Sendo assim, nota-se que a aniquilação deste dispositivo não afetaria a garantia constitucional da vitaliciedade, uma vez que esta garantia não possui o condão de blindar os juízes da prática de atos ilícitos, mas sim, de preservar as funções, prerrogativas e atividades da magistratura.

\section{REFERÊNCIAS}

BRASIL. Constituição (1988). Constituição da República Federativa do Brasil. Brasília, DF: Senado Federal: Centro Gráfico, 1988. Disponível em: http://www.planalto.gov.br/ccivil_03/constituicao/constituicao.htm. Acesso em o7 abril 2021.

BRASIL. Lei complementar n. 35, de 14 de março de 1979, Dispõe sobre a Lei Orgânica da Magistratura Nacional. Disponível em: http://www.planalto.gov.br/ccivil_03/leis/lcp/lcp35.htm. Acesso em o7 abril de 2021 .

PINHO, Debora (2004) Já são mais de ioo os juízes no banco dos réus do país. Revista Consultor Jurídico. Disponível em: ConJur - Já são mais de ıoo os juízes no banco dos réus do País (página 3 de 5), Acesso em i6.abril.2021. I4

GONÇALVES, Jane Reis Pereira $2^{\underline{a}}$ edição, Interpretação Constitucional e Direitos Fundamentais. Disponível em: https://integrada.minhabiblioteca.com.br/books/r. Acesso em i6.abril.2021.

RAMOS, André Tavares, Manual do Poder Judiciário Brasileiro. Disponível em: https://integrada.minhabiblioteca.com.br/\#/books/9788502148277/cfi/238!/4/4@o.00:37.9. Acesso em I6 junho.2021.

CÉSAR, Rodrigo Rebello Pinho I7 ${ }^{\text {a }}$ edição, Da organização do Estado, dos poderese histórico das constituições. Disponível em:https://integrada.minhabiblioteca.com.br Acesso em I6. junho,2021

ANDRADE, Paula (202I) CNJ aposenta desembargador acusado de venda de sentenças em Tocantins. Disponível em: https://www.cnj.jus.br/cnj-aposenta-desembargador-acusadode-venda-de-sentencas-em-tocantins/. Acesso em i6 junhoz2021.

ANDRADE, Paula (2021) CNJ confirma aposentadoria compulsória de juiz de Mato Grosso. Disponível em: https://www.cnj.jus.br/cnj-confirma-aposentadoria- compulsoriade-juiz-do-mato-grosso/. Acesso em I6 junho 202I.

MELO, Jeferson (202I) Desembargadora do TJMS recebe pena de aposentadoria 
compulsória. Disponível em: https://www.cnj.jus.br/desembargadora-do-tjms- recebepena-de-aposentadoria-compulsoria/. Acesso em I7 junho 2021.

SANTOS, Arthur da Silva (202I) Ministro restabelece aposentadoria do exdesembargadorcond enado por vender sentença. Disponível em: https://www.olharjuridico.com.br/noticias/exibir.asnoticia=ministro-osentadoria-de-exdesembargador-condenado-por-vender-sentenca\&edic $\mathrm{ao}=\mathrm{I}$. Acesso em I7 junho 202I.

MARTINS, Flávio $4^{\underline{a}}$ edição, Curso de Direito Constitucional. Disponível em: https://integrada.minhabiblioteca.com.br/\#/books/9788553617883/cfi/953!/4/4@ o.oo:0.0oAcesso em I6. junho 2021.

SANTOS, Cleber de Jesus (2018) A pena de aposentadoria compulsória de magistrados por interesse público e a infringência ao princípio da moralidade administrativa. Disponível em: https://monografias.ufma.br/jspui/handle/123456789/2004. Acesso em i6. junho 2021.

GONÇALVES, Pierry Santos (2020). O contraste entre os princípios da administração pública e a pena aposentadoria compulsória aplicada na magistratura. Disponível em: https://repositorio.animaeducacao.com.br/handle/ANIMA/7394. Acesso em i6. junho202I.

NELTO, José Lagares das Mercês (2020). Projeto de Lei complementar n. 277, de I4 de dezembro de 2020. Revoga a pena disciplinar de aposentadoria compulsória einstitui a pena de demissão aos magistrados condenados pela prática de faltas disciplinares graves. Disponívelem:https://www.camara.leg.br/proposicoesWeb/ idProposicao=22669I 5 . Acesso em 16. setembro 2021.

GUEDES, Paulo Roberto Nunes (2020). Proposta de Emenda a Constituição № 32, altera disposições sobre servidores, empregados públicos e organização administrativa Disponível em :https://www.camara.leg.br/proposicoesWeb/fichadetramitacao $=226208$

3. Acesso em 21. setembro 2021.

BRASIL. Lei 13.105, de 16 de março de 2015, Código de Processo Civil. Disponível em: http://www.planalto.gov.br/ccivil_03/_ato2015-2018/2015/lei/li3105.htm. Acesso em i6. junho 2021.

LEWANDOWSKI, Enrique Ricardo (2014) Presidente do Supremo Tribunal Federal. Minuta de Anteprojeto do Estatuto da Magistratura. Disponível em https://www.conjur.com.br/dl/estatuto-magistratura-juizes-loman-stf.pdf. Acesso em 26. setembro 202I. 